recommendations on a national level. The Patient Panel represents a step forward in international collaboration of PPIE within implementation projects. The Patient Panel is producing culturally appropriate and relevant information and resources for patients in five European countries. Future activities may include the development of patient stories to support increased adoption of JIGSAW-E, providing the patient perspective during training of health care professionals, and the digitisation of patient resources into Smartphone or tablet Apps.

References:

[1] https://goo.gl/a4xYUV.

[2] Blackburn et al. Res. Involvement and Engagement (2016) 2:5. doi: 10.1186/ s40900-016-0019-x.

Acknowledgements: JIGSAW-E is funded via the West Midlands AHSN by EITHealth. Funding from the WM AHSN, the Regional Innovation Fund NHS England and Shropshire CCG. KD is part funded by a Knowledge Mobilisation Research Fellowship (KMRF201403002) from the NIHR.

Disclosure of Interest: None declared

DOI: 10.1136/annrheumdis-2017-eular.2711

\section{AB0818 PERSONALIZED ARTICULATING JOINT DISTRACTION FOR TREATMENT OF TIBIOFEMORAL OSTEOARTHRITIS: CLINICAL FEASIBILITY}

T. Struik $^{1}$, R.J. Custers ${ }^{2}$, N.J. Besselink ${ }^{1}$, J.E. Jaspers ${ }^{3}$, A.K. Marijnissen ${ }^{1}$, F.P. Lafeber ${ }^{1}$, S.C. Mastbergen ${ }^{1}$. ${ }^{1}$ Rheumatology \& Clinical Immunology;

${ }^{2}$ Orthopedics; ${ }^{3}$ Medical Technology \& Clinical Physics, University Medical Center Utrecht, Utrecht, Netherlands

Background: Osteoarthritis (OA) patients encounter progressive pain and functional disabilities, including joint stiffness, due to degeneration of the joint tissues. For knee OA, the most prevalent form, available treatment strategies are limited in number and focus primarily on minimizing the functional disability, inflammation, and pain in a conservative manner since still no unambiguously proven effective disease modifying approaches are available. Progress in the development of joint sparing procedures however, has demonstrated the regenerative capacity of the osteoarthritic knee and with that the delay for conventional last resort therapy such as total knee arthroplasty (TKA). Knee Joint Distraction (KJD) is a joint preserving procedure that can postpone knee arthroplasty in case of knee osteoarthritis for over 5 years [1]. Distraction is applied with an external fixator for 6-8 weeks.

Objectives: To reduce the burden on patients during treatment originating from a restriction in joint flexion during KJD, we evaluated an articulating frame. A personalized articulating KJD-device was developed, biomechanically tested, and technical feasibility was evaluated in cadaveric legs. Reproduction of joint specific motion was demonstrated and articulating KJD was concluded to be technically feasible. In this study, clinical feasibility was tested in 3 patients.

Methods: Patients received rigid knee joint distraction treatment in general practice. After 2-4 weeks, the frame was removed in the outpatient clinic and the joint was flexed in a continuous passive motion (CPM) device until $30^{\circ}$ flexion was reached, or motion became painful. Subsequently, the articulating frame was attached to the bone pins (figure 1), followed by computerized personalization of the hinge from a non-invasive motion measurement. After assembling the custom parts, weight-bearing and non-weight-bearing radiographs were taken at 0,15 , and $30^{\circ}$ flexion for joint space width measurements. Finally, the articulating device was replaced by the rigid frame and treatment was continued according to clinical practice.

Results: For none of the three patients, the articulating distractor could be personalized. In the first patient, $15^{\circ}$ flexion was achieved on the CPM, but pin positions did not allow for positioning of the frame. In the other patients, $8^{\circ}$ and $15^{\circ}$ flexion was measured, which was too little motion for the custom software to generate personalized hinge parts. Pain at the pin sites during motion was reported by all patients.

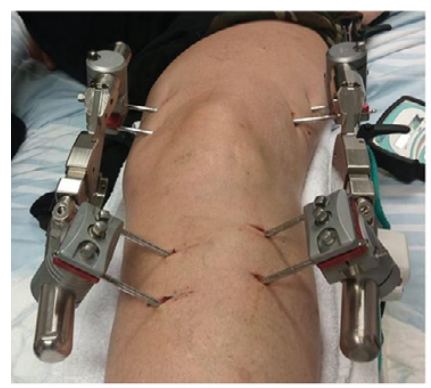

Figure 1 The articulating frame assembled to the same bone pins and bone pin clamps as used for rigid joint distraction in clinical practice, and previous to measurement of joint-specificmotion and customization of joint specific hinge parts.

Conclusions: Despite confirmation of joint-specific articulating distraction on cadaveric legs, clinical feasibility could not be demonstrated, mainly due to painful motion of soft tissues along the bone pins.

References:

[1] Woude J-TAD van der, Wiegant K, Roermund PM van, Intema F, Custers RJH,
Eckstein F, et al. Five-Year Follow-up of Knee Joint Distraction Clinical Benefit and Cartilaginous Tissue Repair in an Open Uncontrolled Prospective Study. Cartilage. 2016 Aug 26;1947603516665442.

Disclosure of Interest: None declared

DOI: 10.1136/annrheumdis-2017-eular.1724

\section{AB0819 IS INCREASING THE TREND OF PRIMARY TOTAL HIP ARTHROPLASTIES FOR THE PATIENTS WITH OSTEOARTHRITIS, BUT DECREASING THE RATE OF WOMEN IN SUPER-AGING AREA OF JAPAN IN LAST TWELVE YEARS?}

Y. Takakubo $^{1}$, K. Sasaki ${ }^{1}$, H. Oki ${ }^{1}$, Y. Naganuma ${ }^{1}$, A. Narita ${ }^{1}$, J. Ito ${ }^{1}$, H. Kawaji ${ }^{2}$, M. Ishii ${ }^{2}$, M. Takagi ${ }^{1}$. 'D Department of Orthopaedic Surgery, Yamagata University Faculty of Medicine; ${ }^{2}$ Department of Orthopaedic Surgery, Yamagata Saisei Hospital, Yamagata, Japan

Background: Elderly people over 65 year-old have increased year by year in many countries ${ }^{1}$. Because their rate was from $19.5 \%$ at 2004 to $26.8 \%$ at 2015 in Japan and $30.8 \%$ at 2015 in our super-aging area, the numbers of total joint arthroplasties have increased too ${ }^{2}$. In fact, the numbers of total hip arthroplasty predicted increasing from six hundred fifty-six thousand cases at 2010 to one million three hundred seventy-six thousand cases at 2020 in USA $^{3}$. The rate of total joint arthroplasty, including primary total hip arthroplasty, may reflect trends in management and health outcomes of elderly people with osteoarthritis $(O A)$ in our super-aging area of Japan ${ }^{1,4}$.

Objectives: The aim of this study was to analyze the trend of primary total hip arthroplasties for the patients with OA in our institutes in the last twelve years. Methods: We surveyed the number and rate of orthopaedic surgeries and primary total hip arthroplasties in our two institutes from 2004 to 2015.

Results: We had 19,862 cases of orthopaedic surgeries, including 3,782 primary total hip arthroplasties in the last twelve years. They have increased year by year $(r=0.92, p<0.05$, Fig. 1). Mean age was 64.5 old-year (62.4-66.8) in last twelve years, had become older year by year $(r=0.78, p<0.05), 62.4$ old-year at 2004 vs 66.8 old-year at 2015. Mean rate of female was $87 \%(85-91)$ in last twelve years, had gradually decreased year by year $(r=-0.68, p<0.05), 91 \%$ at 2004 vs $85 \%$ at 2015.

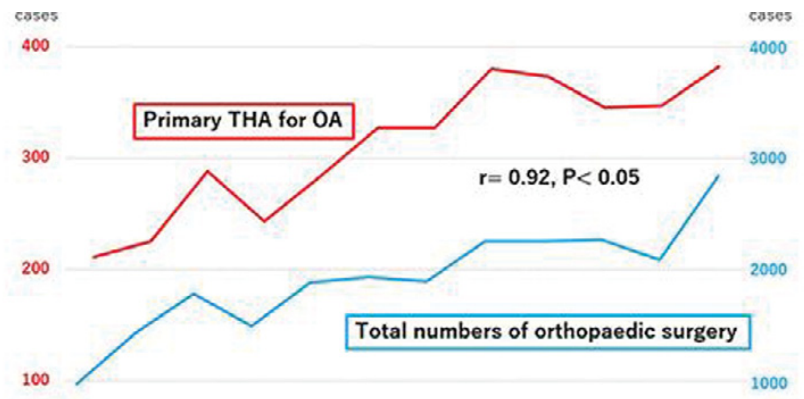

Fig. 1

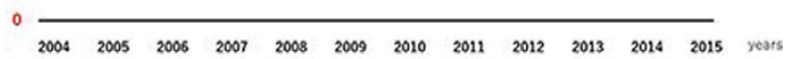

Conclusions: The rate of total joint arthroplasties including primary total hip arthroplasty increased year by year, and related to total numbers of orthopaedic surgeries in our super-aging area of Japan. Mean age at receiving primary total hip arthroplasty was older annually but mean rate of women had gradually decreased year by year. Although majority of OA hip consist of female which have secondary dysplastic acetabulum in our country ${ }^{2}$, it might increase gradually the patients of man with OA hip in super-aging time in Japan.

[1] National Institute of Population and Social Security Research. Japanese Mortality Database, 2014. http://www.ipss.go.jp/.

[2] Jingushi S, et al. J Orthop Sci. 15:626-31, 2010

[3] Kurtz SM, et al. J Bone Joint Surg Am. 96: 624-30, 2014.

[4] Yamagata prefecture, Health and longevity Promotion Section. Rate of elderly people in Yamagata prefecture, 2014. http://www.pref.yamagata.jp/ou/ kikakushinko/020052/tokei/jinkel.html.

Disclosure of Interest: None declared

DOI: 10.1136/annrheumdis-2017-eular.2181 